\title{
SOLVING THE PROBLEM OF SMOKING IN THE POLISH ENTERPRISES DURING 2003-2015
}

\section{ELŻBIETA KORZENIOWSKA and KRZYSZTOF PUCHALSKI}

\author{
Nofer Institute of Occupational Medicine, Łódź, Poland \\ National Centre for Workplace Health Promotion
}

\begin{abstract}
Objectives: Tobacco smoking is a major organizational, economical, and public relations-related (PR-related) problem for the company. Moreover, it is an important health determinant of the working population. The paper reports the results of the research which analyzed the current state and the tobacco control activities' transformations undertaken by Polish employers between 2003 and 2015. Material and Methods: Data comes from the research performed in 2006, 2010 and 2015, involving random-selected representative samples of Polish enterprises, employing no fewer than 50 employees. The sampling pattern covered location and classification of activities (excluding public administration, national defense, social security, education, health care and social assistance sectors). Consecutive interviews were conducted with representatives of 611, 1002 and 1000 companies, respectively. Results: The companies improved their compliance with the national regulations on smoking in the workplace. The strategy for limiting smoking in public places resulted in a steady increase in the number of companies (11\%, 23\%, 38\%, respectively) that introduced smoking ban. Approximately in every second company, smoking was allowed only in the smoking room or outdoors. Voluntary activities (e.g., education and support for employees wishing to cease smoking) were very rarely undertaken by medium and large companies (several percent) and since 2010, when the law had become more restrictive, such tendency reinforced. Employers also were seldom interested in the prevalence of tobacco smoking among their personnel, its consequences for the company's functioning and the effectiveness of the implemented tobacco control measures. Conclusions: National anti-smoking policy caused that companies were more focused on smoking-bans at the expense of education and support for those who wanted to cease smoking. Although this contributes to reducing secondary smoking in the workplace, the companies' potential to become a major agent for tobacco control policies is neglected while the downward trend of smoking in the Polish society has slowed down. Int J Occup Med Environ Health 2018;31(3):261-280
\end{abstract}

Key words:

Workplace health promotion, Smoke-free workplace, Smoking cessation in the workplace, Workplace tobacco control, Workplace tobacco control policy, Quality of workplace tobacco programs

\section{INTRODUCTION}

Recent data shows that, despite systematic reduction of the prevalence of smoking (although, unfortunately, in recent years the reduction has been slowing down) every 4th citizen of our country (about every 5th woman and every 3 rd man) is a smoker [1].

Tobacco smoking is detrimental to the individuals and the society both from health and economic perspective.
It is assumed that, comparing to other behavioral factors, health risks of tobacco smoking are better scientifically documented (smoking contributes, e.g., to the development of ischemic heart disease, cerebrovascular disease, infections of the lower respiratory tract, chronic obstructive pulmonary disease (COPD), cancers of the trachea, bronchi, lungs, and tuberculosis), and are also considered to be a factor increasing the likelihood of disability and

Funding: work supported by Ministry of Science and Higher Education grants for the statutory activities of the Nofer Institute of Occupational Medicine, Project No. IMP 7.6/2016 Fri. "Anti-tobacco activities in Poland-analysis of trends in the years 2006-2015." Project manager: Elżbieta Korzeniowska, Ph.D.

Received: November 28, 2016. Accepted: June 22, 2017.

Corresponding author: E. Korzeniowska, Nofer Institute of Occupational Medicine, National Centre for Workplace Health Promotion, św. Teresy 8, 91-348 Łódź, Poland (e-mail: elzbieta.korzeniowska@imp.lodz.pl). 
premature death [2,3]. Smoking is also expensive. A statistical smoker in Poland spends almost PLN 2000 per year on cigarettes. This means that the purchasing power of a smoker's family is weaker, e.g., in terms of spending on food, but also on culture and education [4]. In the macro scale, the smoking epidemic translates into higher rates of morbidity and mortality (especially due to cancer and cardiovascular diseases) [5] and socio-economic costs, such as burden on the health care system caused by treatment of tobacco-related diseases (e.g., in Poland it is about PLN 18 billion per year) [4]. It has been assessed that in Poland in 2 decades the socio-economic costs connected with second-hand smoking will account to PLN 135 billion whereas the costs of treatment of diseases caused by second-hand smoking is estimated at PLN 22 billion [6]. Thus, reduction of tobacco use is considered to be a major challenge for public health policies in the European Union (EU) countries as well as in the European Union as a whole. Activities to achieve this goal represent 2 analytical approaches. It focuses on convincing people, who are free to make their own choices, about the adverse consequences of tobacco smoking, motivate them not to start, or to quit smoking and offer them a possible comprehensive support for the implementation of the style eliminating tobacco smoke from their life environment $[7,8]$.

The second approach concentrates on the idea of reducing tobacco consumption by implementing the restrictions on smoking, enacted as part of the tobacco-control regulations (in public, administrative, criminal, civil, and labor law). This approach is increasingly denying the idea of individual freedom in the use of tobacco products, and the rationale behind the denial includes adverse effects of tobacco smoking on public health, economic and social facets of human life.

The essence of today's anti-tobacco strategies is reflected in the Framework Convention of the World Health Organization on Tobacco Control of 2003 and its Guidelines (in Poland, it has become effective since 14 Decem- ber, 2006) [9]. These documents instruct, inter alia, the Member States how to protect people from the exposure to tobacco smoke, how to expand the areas covered by the prohibition of smoking, including public places, how to monitor the market of tobacco products, how to control the content of the ingredients in products of this type, how to warn against the adverse effects of smoking through information provided on tobacco product packaging, how to reduce advertising and promotion of tobacco products [9].

Both above mentioned approaches touch upon the problem of reducing the prevalence of tobacco smoking, in the so-called the sphere of work, that is time and place of work. Particular attention is paid to that dilemma in the health promotion approach. The settings-based approach stresses the importance of taking steps to promote health, including tobacco control in environments in which we live (e.g., school, workplace, local community), with due respect to their specific (social, organizational, financial) character, while maintaining the rights of members of a given milieu to assess the situation, propose the desired changes in the region and participate in their implementation and evaluation [10].

According to such an approach, health promotion emphasizes the role of work environment as an important sphere of the adult population functioning, in which it is possible to minimize the number of new smokers, or better cope with nicotine addiction through the development and implementation of workplace-based tobacco-control programs and internal policies [11]. Workplace health promotion programs reach those people who are not reachable through other community programs (non-responders, not interested, denying). As far as smoking is concerned workplace health promotion measures offer possibility to protect non-smokers from involuntary smoking, to offer support for those who would like to quit, and minimize the number of new smokers although it is well known that majority of people had begun to smoke before they were 20 [12]. 
It needs stressing that it is much easier to access employed (than unemployed) people (simply because they are present together at the same place and time); this is true in particular when it comes to the young people who are reluctant to participate in population-targeted health-promotion actions or campaigns. Furthermore, workplace-based health promotion campaigns are more easily implemented and less expensive (e.g., owing to the use of the existing training infrastructure, a company's management, training, safety, and internal interpersonal relations social dynamics experts, including support mechanisms and social control specialists). On the other hand, well-designed tobacco-control projects are beneficial to the companies implementing them, by contributing to the reduction of losses:

- economic (resulting, e.g., from the deterioration of the quality of products or services, reduced effective working time due to cigarette breaks, increased absenteeism of smokers, increase in the cost of fire protection, maintenance, heating, maintenance of premises and equipment),

- social (e.g., lower ability of smokers to perform their duties, smoking-related conflicts),

- reputation [13].

In the other approach, a workplace is primarily a public place, where smoking ban should be obeyed and in the event of non-compliance employee should be subject to penalties (e.g., in Poland, since 1996, companies are obliged to protect the health of non-smoking workers from tobacco smoke in public enterprises, and individual employees violating that regulation are currently at a risk of a fine in the amount of PLN 500). The supporters of that regulation emphasize that such a regulation causes that individuals do not smoke or smoke less, and thus reduce the environmental tobacco smoke in the workplace, which, for example, in Poland affects $34 \%$ of employees or 4.3 million people [14].

As for the practice of tobacco-control measures, complementary combination of these 2 types of interactions would be most desirable. In Poland, however, the stress is rather on the second approach. As mentioned above, since the effective date of the Law on the protection of health against the use of tobacco and tobacco products [15] (hereinafter referred to as the Law on Tobacco Control), enterprises have been among the places where smoking is restricted. Originally (due to ambiguities in the wording of the Law), according to some people, companies employing more than 20 workers were obliged to provide separate rooms for smoking $[15,16]$. Currently, as provided by the amendment of April 2010 to the Regulation quoted above, the employer can independently decide whether to introduce indoor workplace smoking ban or possibly allow for smoking in rooms designed specifically for this purpose.

The measures for health promotion in the workplace are encouraged rather declaratively (e.g., the Position of the Labor Protection Council of the Polish Parliament of 14 November 2006 [17] has never been implemented; the same is true about the Rantanen report of 2012 [18]). The information and education activities addressed to employers and managers, e.g., those justifying the advisability and teaching methods of effective methodologies for comprehensive programs of health promotion implementation and, above all, supporting their implementation (e.g., fiscal measures, organizational, financial support incentives establishing some sort of a partnership between the company and the state to improve the health of the working population) have been neglected. What is more, systemic mechanisms to support such business activity, as part of which programs designed to eliminate tobacco smoke from companies could be implemented, have not been developed.

This approach is illustrated by the document of the Minister of Health of 2013 [17] summing up the activities for the implementation of the project intended to reduce adverse health effects of smoking in Poland during 1997-2013. With regard to the workplaces, those activities were limited to the information on the prohibition of smoking on their premises and regulations concerning the supervision 
of the implementation of the project. The educational activities were addressed to the general public (e.g., in connection with the celebration of the World No Tobacco Day or the World Day of Smoking Cessation), and the most effective ones were said to be those addressed to children aged 5-16 years old.

As to the employees, the information projects designed for officers and employees of the Prison Service, the Police, the State Fire Service, the Border Guard and employees of the Government Protection Bureau may be quoted as praiseworthy exceptions. Moreover, such selective activities were continued during 2004-2018 only for workers of institutions subordinated to the Ministries of: Justice, National Defense, and Home Affairs. These institutions are scheduled to be supported in their attempts to entirely protect their personnel from tobacco smoke in the context of their efforts to ensure safe and healthy working conditions and provide tobacco-control education [19]. Hence, there is no strategy that would involve all our employers in reducing the prevalence of smoking.

The span of efforts to prompt companies in Poland to implement healthy lifestyles, including reduction of tobacco consumption, are rather limited due to narrow support from public funds, mainly by the National Centre for Workplace Health Promotion, Nofer Institute of Occupational Medicine, Łódź. Among other things, in 1996 and 1998, the Centre issued the country's first guidebook presenting a model methodology for tobacco control activities in the workplace, during the period, 1991 to 2001, carried out the project "Smoke-free Workplace" and, among others, sent information packages on-site programs about the problems of anti-smoking in 9000 companies [20]. In the years 2012-2014 in the framework of the "Prophylactic programme to prevent addiction to alcohol, tobacco and other drugs," co-financed by the Swiss program of cooperation with the new EU member states, the Centre prepared and published (this time also in the Internet) another package of educational materials (the guide, brochures, presentations, infographics), and consulted the implementation of health-related projects in more than 200 companies.

The Centre also tries to encourage decision-makers to be more involved in the process. Unfortunately, the achieved success is disproportionate to the needs. When it comes to decision-makers, the winning option is to attempt tobacco control through restrictive regulations. Consequently, there is no funding for social marketing addressed to employers and managers, motivating them to undertake non-compulsory measures to promote health, including tobacco control, and strengthen their determination to find and make use of systems that would help them in the implementation of those measures.

One of the projects implemented by the team of the National Centre for Workplace Health Promotion involves monitoring the activity of medium-sized and large enterprises in Poland in terms of solving the problem of smoking among their personnel. The purpose of this paper is to present the trends in that respect over the last 12 years. In line with the above mentioned external circumstances of such commitment, attention will be paid to the extent to which employers respect the regulations restricting smoking and to the non-compulsory measures undertaken by the employers, including educational support for nonsmoking among their personnel. Thus, the diagnosis based on the results of our research shall contribute to the process of assessing the impact of national legal regulations, as a method of coping with the problem of exposure to tobacco smoke among the working population, including a reduction in the prevalence of nicotine addiction. In addition, it will be crucial for improving the quality of activities including dissemination of the methodology for health promotion programs in the workplace, with focus on the problem of smoking, which is another method of achieving the purposes outlined above. Such a general overview on how workplaces cope with the problem of smoking also provides some useful knowledge to profes- 
sionals offering specific services to employers associated with tobacco control (including those belonging to occupational health services) and internal structures dealing with health management in companies.

\section{MATERIAL AND METHODS}

The article presents the results of the research conducted in the last months of 2006, 2010 and 2015. They diagnose the extent and method of engaging companies in Poland in tobacco control activities in the last 2-3 years prior to the moment of data collection. Thus, it seems reasonable to assume that they present the situation in the period of 12 years. Such a choice of the consecutive releases of the survey allows for a comparison of what happened in the first period of the Act of 9 October 1995 on the protection of health from the effects of use of tobacco and tobacco products [15] with what occurred in connection with its "April amendment" [21] (which, among others, expanded the areas covered by the prohibition of smoking to include most public places, unified sanctions for non-compliance, tightened the rules on advertising of tobacco products), and with the state of things which took place after 5 years of its introduction, and before another amendment, passed in 2016 (in connection with the EU directive on tobacco) [22].

The companies were recruited at random as the representative of the total number of Polish enterprises employing over 50 employees. The stratified sampling schedule took into account the location (all provinces), type of activity (Statistical Classification of Economic Activities in the European Community - NACE) section, earlier according to NACE 2002 [23], then according to the ordinance of the Council of Ministers dated 24 December 2007 on the Polish Classification of Economic Activities [24], excluding enterprises belonging to public administration and defense, mandatory social security, education, health care and social assistance), and the number of employees (in increments: 50-249, 250-999, 1000 and more).
The first survey covered 611 enterprises, the second one - 1002 enterprises, and the third one - 1000 enterprises. The first survey was carried out through the classic interview questionnaire, the next ones - through standardized computer-aided telephone interviews (CATI). A company (an enterprise, factory) was the survey unit, and a random-selected single member of a company's executive personnel (e.g., from health and safety department, human resources, management board) was interviewed. Due to the fact that in each edition of the survey interviews were conducted in the representative samples of companies, the scale and reasons of refusal to take part in the surveys were not analyzed.

Questionnaire sheets (basic version and its subsequent versions with minor modifications) had been developed by the National Centre for Workplace Health Promotion at Nofer Institute of Occupational Medicine, Lódź. Field surveys were performed by professional survey companies (PBS DGA Co. Ltd. from Sopot, PBS Obserwator from Krakow, and the Biostat Group from Rybnik). Due to the fact that the analysis was intended to indicate trends rather than to provide a detailed comparison between the results of the consecutive release of the survey, it had been assumed that some of the differences between their individual stages (due to, e.g., modification of how to conduct an interview, or the fact that the data was collected by different research centers) were negligible. The Table 1 depicts companies taking part in 3 surveys showing their ownership, economic condition and the amount of employees.

Empirical material from the 3 studies was used as the basis of the diagnosis concerning:

- regulations on smoking at work adopted by companies;

- the extent to which those regulations are obeyed by the personnel and supervision by the management of the observance of the regulations, including the application of penalties for non-compliance;

- non-compulsory tobacco-control measures implemented by the company; 
Table 1. Characteristics of the representative samples of Polish companies taking part in 3 surveys on tobacco smoking in 2006, 2010 and 2015

\begin{tabular}{|c|c|c|c|}
\hline \multirow{2}{*}{ Characteristics } & \multicolumn{3}{|c|}{$\begin{array}{c}\text { Companies in subsequent surveys } \\
{[\%]}\end{array}$} \\
\hline & $\begin{array}{c}2006 \\
(\mathrm{~N}=611)\end{array}$ & $\begin{array}{c}2010 \\
(\mathrm{~N}=1002)\end{array}$ & $\begin{array}{c}2015 \\
(\mathrm{~N}=1000)\end{array}$ \\
\hline \multicolumn{4}{|l|}{ Ownership } \\
\hline public & 19.0 & 16.4 & 4.3 \\
\hline private with Polish capital & 50.6 & 48.7 & 85.0 \\
\hline private with foreign capital & 12.8 & 17.6 & 4.7 \\
\hline mixed & 3.6 & 7.4 & 4.6 \\
\hline other/hard to assess & 14.0 & 9.9 & 1.4 \\
\hline \multicolumn{4}{|l|}{ Number of employees ${ }^{\mathrm{a}}$} \\
\hline $50-100$ & 39.5 & 30.2 & 67.7 \\
\hline $101-500$ & 43.5 & 59.3 & 29.7 \\
\hline$\geq 501$ & 17.0 & 10.5 & 2.6 \\
\hline \multicolumn{4}{|c|}{ Self-assessed economic condition 2 years before the interview ${ }^{\mathrm{a}}$} \\
\hline very good & 17.7 & 13.1 & 10.3 \\
\hline rather good & 58.6 & 50.1 & 82.0 \\
\hline the situation was changing & 16.7 & 24.0 & 6.2 \\
\hline rather poor or very poor & 4.2 & 6.3 & 0.3 \\
\hline it is hard to say & 2.8 & 6.5 & 1.2 \\
\hline
\end{tabular}

${ }^{\text {a }}$ On the basis of information given by the respondents in the interviews.

- the quality of companies' projects from the point of view of standard methodologies for the promotion of smoking cessation among employees. The focus was on issues such as: knowledge of the scale of cigarettes consumption problem by the personnel, analyzing the effects of that phenomenon on the company's functioning, the level of employee participation in the development of occupational regulations on smoking, presence of any internal documents relating to solving the problem of smoking and evaluation and anti-smoking activities;

- in addition, selected parameters of the overall social climate related to the problem of smoking in the company, such as groups interested in limiting/eliminating smoking at work, smoking-related conflicts in the com- pany, the attitudes to e-cigarettes (data from the last survey only), were analyzed.

It was also tested whether there was a connection between the phenomena analyzed above and the number of employees in the company or its financial condition. The statistical analysis was conducted with the use of Statistica computer program. The statistical dependence was measured by Perason's $\mathrm{Chi}^{2}$, it was assumed to be statistically significant at $p<0.05$. All relationships between the variables presented in the paper are statistically significant.

\section{RESULTS}

\section{Restrictions on smoking at work}

In the first analyzed period (2006 survey), a total ban on smoking during working hours, irrespective of the work- 
Table 2. Compliance of employees with the rules on tobacco smoking at work valid in representative samples of Polish companies taking part in 3 surveys on tobacco smoking in 2006, 2010 and 2015

\begin{tabular}{lccc}
\hline \multirow{2}{*}{\multicolumn{1}{c}{ Employees' adherence to smoking rules }} & \multicolumn{3}{c}{ Companies in subsequent surveys } \\
& \multicolumn{3}{c}{$[\%]$} \\
\cline { 2 - 4 } & 2006 & 2010 & 2015 \\
$(\mathrm{~N}=537)$ & $(\mathrm{N}=986)$ & $(\mathrm{N}=975)$ \\
\hline Positively yes & 57 & 50 & 76 \\
Rather yes & 28 & 29 & 22 \\
Sometimes yes, sometimes not & 12 & 17 & 2 \\
Rather/positively not & 3 & 4 & 0 \\
\hline
\end{tabular}

er's location, was introduced by approximately every 10th company; in about every 4th company such ban was valid within the premises of the company (with the option of smoking only outside); in nearly $1 / 3$ of companies, smoking was allowed in smoking rooms designed for that particular purpose. A similar fraction of the companies allowed for smoking in designated, equipped in ashtrays places (i.e., in the corridors, staircase). In addition, more than every 10th company did not apply any regulations.

When it comes to 2010, just after the Law on Tobacco Control became more restrictive, a total ban on smoking at work had been introduced by $23 \%$ of companies, $54 \%$ had allowed to smoke in the smoking room and on the outside of the building(s), and $23 \%$ had regulations incompatible with the law (e.g., smoking was permissible in the corridors), or had not had any relevant regulation.

A few years after the Act [15], i.e., around 2015, total ban on smoking at work, indoors and outside of the company buildings had been introduced by $38 \%$ of the companies, a total ban on smoking on the premises of the company, but combined with the possibility of smoking outdoors had been introduced in $30 \%$ of the companies. Twenty-three percent of the companies had adopted regulations whereby tobacco smoking had been permitted only in closed smoking rooms and outdoors. Eight percent of the companies reported that they had not met the requirements of the tobacco control act $(5 \%$ had permitted smoking in marked places, had equipped with ashtrays, e.g., in the corridors, changing rooms, in $3 \%$ there had been no relevant regulations).

When it comes to compliance with the internal rules on smoking by the personnel, according to the data for 2006 and 2010, it was at a very unsatisfactory level. Generally desirable state prevailed only in every second mediumsized and large enterprise. However, around 2015, there was a major improvement. Personnel of 3 quarters of companies behaved properly, and the regulations were disobeyed only in every 50th company. It should be noted, however, that still in every 5th company, although the situation was satisfactory, there was a need for further disciplining employees in that respect (Table 2).

A similar situation occurred in the case of supervision by superiors in compliance with the relevant company regulations on tobacco smoking. This is illustrated in the Table 3. Apparently their involvement increased in that respect around 2010, as 4/5 of them tried to consistently fulfil their duty, while in the previous years the respective quantity had been a half or nearly 2 out of 3 . Unfortunately, still every tenth company needed further improvements.

As to the application of penalties for disobeying the rules on tobacco control at work, they were more often reprimands than fines (Table 4). Specific apogee in the use of warnings and reprimands was shown by the 2010 survey. Such a situation prevailed in over $40 \%$ of companies, while in the earlier and the later survey the same was true 
Table 3. Enforcement by management of the rules on tobacco smoking valid in representative samples of Polish companies taking part in 3 surveys in 2006, 2010 and 2015

\begin{tabular}{|c|c|c|c|}
\hline \multirow{2}{*}{ Smoking rules enforced by management } & \multicolumn{3}{|c|}{$\begin{array}{c}\text { Companies in subsequent surveys } \\
{[\%]}\end{array}$} \\
\hline & $\begin{array}{c}2006 \\
(\mathrm{~N}=536)\end{array}$ & $\begin{array}{c}2010 \\
(\mathrm{~N}=986)\end{array}$ & $\begin{array}{c}2015 \\
(\mathrm{~N}=975)\end{array}$ \\
\hline Consistently & 54 & 62 & 83 \\
\hline Sometimes yes, sometimes not & 31 & 26 & 10 \\
\hline Usually not & 15 & 7 & 0 \\
\hline Hard to say & - & 5 & 1 \\
\hline
\end{tabular}

"-" - the question was not included in the survey.

Table 4. Application of penalties for non-compliance with tobacco-control regulations in representative samples of Polish companies taking part in 3 surveys in 2006, 2010 and 2015

\begin{tabular}{|c|c|c|c|}
\hline \multirow{2}{*}{ Type of disciplinary steps } & \multicolumn{3}{|c|}{$\begin{array}{c}\text { Companies in subsequent surveys } \\
{[\%]}\end{array}$} \\
\hline & $\begin{array}{c}2006 \\
(\mathrm{~N}=611)\end{array}$ & $\begin{array}{c}2010 \\
(\mathrm{~N}=1002)\end{array}$ & $\begin{array}{c}2015 \\
(\mathrm{~N}=1000)\end{array}$ \\
\hline Warnings and reprimands & 23 & 42 & 23 \\
\hline Fines & 10 & 12 & 12 \\
\hline
\end{tabular}

for 1 company in 4 . The frequency of disciplining by means of fines remained at a similar level and was about every 10th company in the analyzed period.

\section{Extra-obligatory tobacco control activities in the workplace}

The Table 5 shows the frequency of measures undertaken by small and medium enterprises in our country other than those prescribed by the tobacco control law. It includes 2 basic types: educational, namely those aimed at increasing the knowledge of the personnel about the phenomenon of smoking and non-smoking motivation, and providing support for those employees who wish to cease smoking. In addition, it illustrates the use of the company's activities to increase the likelihood of recruiting non-smokers.

Classical educational activities addressed to the general personnel (i.e., distribution of leaflets, posters, guides, training) were implemented in the reported period by at most each 4th company, and on the average, by every 5 th company, hence rather rarely. Their popularity was the greatest around 2010. Afterwards the popularity decreased to only $3 \%$ and $1 \%$ in the preceding years and in 2015 , especially the distribution of guides to help people cease smoking and training courses. The phenomenon of involving families in tobacco control activities was practically nonexistent, and bonuses for not smoking at work were very rare. The extent of activities intended to assist employees in ceasing their addiction to nicotine was also very small. On average, only every 16th company decided to respond to such a challenge. In addition, there was a downward trend in each of the forms of such support reported in the survey. In fact, companies did not actually undertake this kind of activity. They almost completely failed to encourage their employees to participate in nationwide smoking-cessation 
Table 5. Activities undertaken to prevent tobacco smoking in representative samples of Polish companies taking part in 3 surveys in 2006, 2010 and 2015

\begin{tabular}{|c|c|c|c|}
\hline \multirow{2}{*}{ Activity } & \multicolumn{3}{|c|}{$\begin{array}{c}\text { Companies in subsequent surveys } \\
{[\%]^{\mathrm{a}}}\end{array}$} \\
\hline & $\begin{array}{c}2006 \\
(\mathrm{~N}=611)\end{array}$ & $\begin{array}{c}2010 \\
(\mathrm{~N}=1002)\end{array}$ & $\begin{array}{c}2015 \\
(\mathrm{~N}=1000)\end{array}$ \\
\hline $\begin{array}{l}\text { Distribution of materials (leaflets, posters, etc.) } \\
\text { on the harmful effects of tobacco smoking }\end{array}$ & 15 & 24 & 17 \\
\hline $\begin{array}{l}\text { Distribution of materials (e.g., guide books) } \\
\text { on the methods for smoking cessation }\end{array}$ & 10 & 15 & 3 \\
\hline $\begin{array}{l}\text { Training of employees (lectures, talks) } \\
\text { on the problem of tobacco smoking }\end{array}$ & 8 & 18 & 1 \\
\hline $\begin{array}{l}\text { Implementation of family-based smoking prevention support } \\
\text { activities (e.g., anti-nicotine quizzes for children, parties, etc.) }\end{array}$ & 1 & - & 0 \\
\hline Regular premiums for not smoking during work time & 2 & 2 & 1 \\
\hline $\begin{array}{l}\text { Encouraging the employees to participate } \\
\text { in tobacco-control events (such as, e.g., "The day without } \\
\text { a cigarette" or "Quit smoking with us") }\end{array}$ & 11 & 11 & 1 \\
\hline $\begin{array}{l}\text { Advertising of tobacco-control therapies accessible } \\
\text { outside the workplace }\end{array}$ & 3 & 6 & 0 \\
\hline $\begin{array}{l}\text { Individual medical advice encouraging to abstain } \\
\text { from tobacco smoking }\end{array}$ & 5 & 10 & 0 \\
\hline Group training sessions for employees willing to quit smoking & 1 & 2 & 0 \\
\hline $\begin{array}{l}\text { One-time premiums for the employees who have decided } \\
\text { to abstain from tobacco smoking }\end{array}$ & 2 & 3 & 1 \\
\hline $\begin{array}{l}\text { Sponsoring of medicines that help the employees } \\
\text { to quit tobacco smoking }\end{array}$ & 1 & - & 0 \\
\hline Preferences for non-smokers during recruitment of new employees & 8 & 6 & 1 \\
\hline
\end{tabular}

a The percentage shares do not add up to 100 because the companies showed all their activities.

"-" - the activity was not included in the survey.

campaigns, previously supported by every 10th company. The preference for non-smokers applying for a job in the company was also marginal.

\section{Quality of tobacco control projects}

\section{implemented in the workplace}

From the companies' point of view upon the standard methodologies of banning tobacco smoke, a crucial issue is a diagnosis that allows to determine the needs and challenges in this regard. The accessible studies examined the implementation of 2 key areas of such initial diagnosis, namely, the prevalence of smoking among personnel and its implications for the development of the company. As far as monitoring of the prevalence of smoking in firms is concerned, it has become evident from the results of the study performed in 2006 that $17 \%$ of companies had a general data on the number of employees who smoked, while only $0.5 \%$ of companies had more detailed information, e.g., on the intensity of smoking. In 2010 and during the preceding 2-3 years, every 3rd company had such gen- 
eral information, and 2\% had additional data. In 2015, the situation was the same, the corresponding numbers being $34 \%$ and $3 \%$, respectively. As for the analysis of the effects of tobacco smoking by employees on the functioning of the company, our earliest study showed that only $5 \%$ of all surveyed companies tackled that issue, while in the next release of our survey the corresponding proportions were $13 \%$ and the last $31 \%$, respectively. Therefore, this problem was being more and more often perceived, although 2/3 of medium-sized and large companies in Poland were still ignorant to the prevalence of smoking among their personnel and its consequences for the functioning of the company.

Other important qualitative determinants of activities for tobacco control include, on the one hand, the necessity to establish partnership and conciliatory relations with the employees and, on the other hand, present the adopted tobacco control strategies in the form of an internal document, thus making it easier for the personnel to become familiar with and obey them.

The extent of consulting with the employees the decision on smoking control in the consecutive periods was as follows. According to the data for 2006, only $15 \%$ of companies asked for the opinion of all employees and nearly 1 out of 5 consulted them with some of their representatives/organizations. As much as a half of the companies introduced tobacco control without such consultations. Around 2010, approximately every 4th company consulted those issues with all their employees, and every 3rd consulted on the issues with the representatives of the personnel. Every 3rd company also implemented tobacco control measures without prior discussion with the personnel. According to the 2015 data, 61\% of companies agreed implementation of anti-tobacco regulations with all employees, $14 \%$ - with their representatives/associations, and less than in every 5th this was done without any such procedures. Regarding the formalization of the decisions on tobacco control in the workplace by includ- ing those decisions in companies' internal documents, in the 1st, 2nd and 3rd release of the reported research, the proportions of the companies that formalized tobaccocontrol measures were $54 \%, 68 \%$ and $65 \%$, respectively (while the proportions of the companies which did not do it were $46 \%, 27 \%$ and $25 \%$, respectively).

Evaluation of measures taken to minimize the problem of tobacco use by employees was an important element motivating and enabling companies to improve those measures. The reported study focused on the assessment of the implemented regulations consequences, and other occupational activities of tobacco control in the company. Around 2006, as much as $93 \%$ of the companies did not attempt such evaluation, while around 2010 and 2015, the percentage shares of companies that did not attempt such activity were $71 \%$ and $61 \%$, respectively. Thus, the resultant data confirmed a frequent tendency to neglect such assessments. Although this neglect was no longer as widespread as in 2006, still close to 2/3 of companies did not observe what was the result of the internal measures taken to control tobacco smoking among the company's personnel.

\section{Overall social attitudes towards the problem of smoking in the company}

The diagnosis of this phenomenon focused on finding companies that were supporters of regulations and other measures relating to smoking, whether there were smoking-related conflicts and, in the recent survey, what the attitude to the use of e-cigarettes by workers was.

As regards the issue of fostering regulations and activities within the company which related to smoking, the data on this subject is provided in the Table 6 .

In each release of the survey, the company management was most frequently indicated as the supporter of tobacco control followed, at a considerably lower frequency, by the personnel of health, safety and personal resources departments. The 3 rd supporter group consisted of non- 
Table 6. Supporters of actions intended to ban tobacco smoke in the company in representative samples of Polish companies taking part in 3 surveys in 2006, 2010 and 2015

\begin{tabular}{lccc}
\hline & \multicolumn{3}{c}{ Companies in subsequent surveys } \\
\multicolumn{1}{c}{ Supporter groups } & 2006 & 2010 & 2015 \\
& $(\mathrm{~N}=512)$ & $(\mathrm{N}=943)$ & $(\mathrm{N}=975)$ \\
\hline Company management & 74 & 56 & 81 \\
Employee organizations (trade unions) & 7 & 4 & 10 \\
Departments of: safety, environment protection, & 60 & 45 & 25 \\
$\quad$ human resources, etc. & 31 & 20 & 10 \\
Non-smoker employees & 1 & 3 & 3 \\
Smokers hoping for smoking-cessation support & 1 & 1 & 10 \\
Other group & 7 & 12 & 3 \\
No supporters of such actions & & & \\
\hline
\end{tabular}

smoker employees. The data proved that neither active smokers did actively search for a company's support to cease smoking nor trade unions showed interest in the problem. It appeared that more stringent stance on tobacco smoking, as reflected by the changes made to the Law on Tobacco Control in 2010 [21], unavoidably expanded the activity of management in the coming years to favor taking firm decisions in this regard. This is illustrated by almost $30 \%$ rise in the frequency of indicating that group in the period 2010-2015 as the supporters of solving the problem of smoking. It was, in a quite natural way, accompanied by a decreasing activity of professionals of other departments dealing with the health of employees, and non-smokers. It seems quite reasonable to assume that the "health-involved" professionals merely executed the decisions taken by the company's management, while the non-smokers were simply "reaping the rewards." Interestingly, only small percentage shares of companies reported their lack of allies for anti-tobacco activities among their personnel. The increase in such behavior to a level of approximately every 10th company occurred when the more restrictive law was implemented, which was shown in the 2010 survey, and then dropped to $3 \%$ according to the data for 2015 .
Contrary to the popular belief, smoking was not a problem that would give rise to any discernible company-wide conflicts, both when it comes to relationships among employees or between superiors and subordinates. The respondents representing 93\%, 75\% and $97 \%$ of companies (for 2006, 2010 and 2015, respectively) did not mention conflicts between smoking and non-smoking employees and 92\%, 87\% and 96\% when it comes to conflicts between management and personnel. It seems that some intensification of conflicts occurred during the implementation of the April amendment to the Law on Tobacco Control [21], which took place in the end of 2010, both between management and personnel as well as between the smoker and non-smoker employees. Perhaps they were granted by the employer (the owner or operator) the right to decide whether to introduce a total ban on smoking or continue smoking as permissible in smoking rooms or off the premises of the company. As you can see, the situation calmed down and after 5 years, the conflicts were only of marginal significance.

An interesting problem was companies' attitude to e-cigarettes. They appeared in Poland in 2006 and evidently became popular in 2008 and 2009. It seems reasonable to assume that e-cigarettes were used by a few percent 
(3-7\% according to various data) of the population aged 15 years old and older [25]. They have their detractors (among people opting for the complete eradication of nicotine dependence) and supporters (who argue that they are effective in reducing adverse effects of tobacco smoking). The study conducted in the end of 2015 undertook the problem of the company's attitudes towards e-cigarettes. The results showed that as many as $71 \%$ of companies were not interested in whether employees used ecigarettes or not, $13 \%$ of the companies limited their use, and $1 \%$ of the companies completely banned their use. Every 16th company promoted e-cigarettes as a healthier form of smoking. Nearly every 10th company experienced difficulty in taking a position in this regard.

\section{Size and condition of the company and its tobacco control activity}

In 2006 and during the preceding 2-3 years, the economic condition of companies exerted a statistically significant effect on the level of compliance by employees to the rules on smoking control adopted by their companies, and on the enforcement of those rules by the management. In companies with weak financial situation, the results were poorer. In addition, that type of companies experienced more frequent smoking-related conflicts between personnel and management. When it comes to the size of the companies, in those employing up to 100 employees, tobacco-control consultations with the whole personnel were most frequent, while similar consultations were least frequent in the largest companies. On the other hand, the larger the company the more likely the tobacco-control regulations were recorded in the internal documents.

According to the data from 2010, there was no relationship between the economic condition of the companies and their attitude to smoking. On the other hand, it appeared that the larger the company, the more often it conferred formal status upon the internal regulations on the problem of smoking, organized smoking rooms and implemented extra-statutory tobacco control measures. In contrast, smaller companies were more ignorant about the prevalence of smoking among their personnel, less frequently consulted tobacco-control regulations with all their employees and more frequently implemented the regulations arbitrarily without any consultations, had no records on that subject in the internal documents and introduced a total ban on smoking at work, or made smoking permissible only outside of their premises.

Findings from 2015 showed that better economic conditions favored consulting of introduced anti-tobacco regulations with the personnel, recording those regulations in the internal documents and implementing them 2-3 years preceding the survey. As to the company size, the companies employing over 501 people usually introduced a total ban on smoking at work and less consistently monitored the compliance with the adopted tobacco control rules. Smaller companies, just as before, better knew the prevalence of smoking among their personnel and more often consulted measures to be undertaken on tobacco control with all employees.

\section{Summary}

The data showed that over the years 2003-2015, there was a significant change in the companies' attitudes towards implementing relevant national smoking-control regulations. At the beginning of that period, nearly a half of the companies did not obey those regulations (acted unlawfully or were not at all interested in this issue), while at the end of that period only about 1 in 10 reported such disobedience. However, there was a consistent increase in the proportion of companies implementing a total ban on smoking at work $(11 \%, 23 \%, 38 \%)$.

Around 2010, it was also fairly common to isolate the smoker from the non-smoker employees, not only by providing a smoking room, but also by bringing the smokers out, to the outside of the company's buildings. According to the 2010 data, such measure was taken by a half 
of the enterprises, for 2015 - the corresponding number was 1 out of 4, but at the same time almost 1 company out of 3 permitted smoking only outdoors. In the event that companies could also offer their own assessment (as it was the case during the 2015 interview) of what changes had occurred in connection with the amendment of the 2010 regulations on smoking in public places, including workplaces, it turned out that only $7 \%$ of them considered that the situation remained the same, while $89 \%$ of respondents claimed that smoking had become limited. Only less than $3 \%$ indicated that the smokers were more at ease. A similar fraction of respondents were no table to provide any answer to such a question.

As to obeying - by a personnel - the tobacco-control regulations currently in force in their companies, the implementation of more stringent law resulted in an improvement, but still every 4th company should strive to improve in that respect. The company management also tended to more consistently monitor the level of compliance by the employees to the tobacco-control regulations, and this trend was intensified in 2010-2015. But the problem was not satisfactorily solved in about every 10 th company. Penalties, as a method of dealing with it were mostly used by companies around 2010. This was true about more than a half of them. According to the findings of 2015, penalties were applied in every third company, while warnings and reprimands were twice more frequent than fines.

Voluntary tobacco control actions were taken very rarely by medium and large companies in our country (a few, or exceptionally an extra dozen percent or so). After a slight increase in the interest in educational activities around 2010, the companies practically did not undertake them. (This is particularly true with tobacco control training and providing smoking-cessation guides to the personnel.) A bonus paid for not smoking at work was an extremely rare practice. Active support for employees wishing to cease smoking was also neglected. After a slight increase in the interest in their problem (manifested, e.g., by promotion of tobacco-control therapy or provision of individual medical advice) in 2010, there was complete regression in this regard.

As to the general quality of the approach of the studied companies towards solving the problem of smoking during working hours, it is far from optimum in the light of model methodologies. In particular, the companies lacked information about how a big challenge it was in their instance. The data indicated that companies showed little interest in the scale of smoking among their employees. In 2006 and during the 2-3 preceding years, only every 5 th company had data on this subject. At the time when tobacco control rules were tighter, there was some improvement in this regard, but still about $2 / 3$ of the companies were not interested in the extent of this phenomenon. There was, however, a clearly growing interest in the impact of tobacco smoking by the personnel on the company's efficiency. By the 2006 survey, the problem was considered only by every 20th company, while currently it is studied by every 3 rd company. However, this index is still very low.

The situation is better when it comes to taking into account the opinion of a company's personnel on the adopted tobacco control measures. While at the beginning of the analyzed period, such opinions were collected from all employees or their representatives only by every third company, around 2010 the opinions were collected by more than a half, and currently they are collected by 3 quarters of the companies. This is a positive phenomenon, the more so that there is a growth in the percentage share of companies that declare consultations with each employee. However, we must remember that the final interpretation of this fact is very dependent on the extent and manner in which those consultations are performed, but, unfortunately, no such data is accessible.

Moreover, according to the 2010 data, it has become a little more frequent than before to formalize decisions on tobacco control by including them in the internal documents (ordinances, regulations). Since then, the situation 
is similar; currently, 2/3 of companies behave like that. Unfortunately, the assessment of the effects of tobaccocontrol measures continues to represent a serious problem. A significant proportion (about 2/3) of companies do not have the habit of analysis. Given the small number of those that carry out activities other than those arising from the statutory provisions, it is reasonable to suppose that it is the effect of laws restricting smoking at work that are predominantly disregarded in the analysis, which means that the tobacco-control measures resulting from current legal regulations are implemented fairly mechanically.

When it comes to a general social climate about the phenomenon of smoking during work, it has become evident that the advocates of the implementation of measures to reduce smoking include primarily managements of the companies, followed by departments responsible for safety, health and human resources and the non-smoking personnel of the company. Trade unions seldom become involved in that sphere, and instances of smoker employees seeking for smoking cessation support are extremely rare. After 5 years following the moment when the tobacco control law had been made more restrictive, company managements not only have been seen most frequently in such a role, but increasingly have outrun in that respect other individuals and groups among the personnel. At the same time, the resistance to measures undertaken to control tobacco smoking in the workplace becomes weaker. This is confirmed by findings on conflicts around the problem of smoking in the workplace. According to the 2006 and 2015 data, the overwhelming majority of representatives of the companies did not identify such phenomena among its personnel. Only in the 2010 study, i.e., during the implementation of the stringent restrictions on tobacco smoking, every 7 th company experienced tensions between the personnel and the management, and every 4th - between smoking and non-smoking employees.

As for e-cigarettes, their emergence and spread is not as yet a problem for companies. Nearly 3 quarters of the companies are not interested in how they are used by the personnel. It turns out, however, that if this issue is recognized, the companies tend rather to restrict their use (every 7th company) than regard e-cigarette use as an advisable method for limiting traditional smoking (every 16th company).

Companies' economic condition and size do not significantly affect their attitude to the problem of smoking. Better financial situation in the first and the last of the analyzed periods favored workers' compliance with the new tobacco-control legislation, and currently it also favors consulting of tobacco-control measures with employees and including them in the internal documents. In small companies, it was more usual to agree the tobaccocontrol measures with the employees rather than to include them in formalized internal regulations.

\section{DISCUSSION}

The findings cannot be related to similar diagnoses of this kind in our country because such research has not been performed. Some external view of the situation, but limited solely to obeying by companies the regulations on tobacco control, may be obtained from the Chief Sanitary Inspectorate (Główny Inspektorat Sanitarny - GIS) monitoring data. They show a better situation in that respect than that portrayed by the results of the survey reported above. According to the 2014 GIS data, only $0.1 \%$ of the 70258 inspected companies have not implemented the law [26]. However, according to the 2015 internal evaluation of representatives of companies, $8 \%$ of companies do not meet the requirements of the relevant law (in $5 \%$ of the monitored companies smoking is permissible in specifically designated places equipped with ashtrays, e.g., in the corridors, changing rooms, while in $3 \%$ of the companies, smoking is not regulated at all), in as many as every 4th company the relevant regulations are not fully obeyed by the employees, and nearly in every 5th company, the management has problems with consistency in the supervision 
of the compliance to the law. Such divergence in the assessment of the extent of respecting the law on tobacco control by companies in Poland makes it reasonable to presume that the monitoring lacks deeper insight, since in their self-evaluation, companies see more trouble with respecting the law in Poland (a similar situation occurred also during the previous release of the survey).

However, there is data proving that employers show interest in tobacco-control activities undertaken by employees. According to the 2010 findings of the National Centre for Workplace Health Promotion, Nofer Institute of Occupational Medicine, approximately every 10th employee in our country expects education on, and support in the struggle against addiction to nicotine [27], and according to the 2014 The Confederation of Polish Employers (Pracodawcy Rzeczypospolitej Polskiej - PRP) and Luxmed data, the smoking-cessation support is expected by nearly every fifth employee [28]. Thus, the involvement of companies is therefore below the expectations of the workers.

However, the relationship between the cited 2015 studies may be observed, with respect to:

- the fact that nearly $90 \%$ of the surveyed companies used the opportunity to implement various bans on smoking at work,

- a clear invigorating of the companies' boards in the role of banning tobacco smoke supporters in the work environment,

- decrease in the percentage share of enterprises in which there are no allies for this type of measures, and those concerning the attitudes of the Polish society against restrictions on smoking in public places, collected in connection with work on more restrictive law on tobacco control.

They illustrate a positive social climate towards these changes. Already in December 2010, according to the data from the Center for Public Opinion Research (Ośrodek Badania Opinii Publicznej - TNS OBOP), $62 \%$ of adults felt that appropriate adjustments had been made to the Law on Tobacco Control [29] while in 2012 up to 84\% supported, e.g., the ban on smoking in public places, while the number of opponents of these measures decreased [30]. As for the ban on smoking at workplaces, only the findings for the earlier period are accessible, but they also show a similar trend, because only $27 \%$ accepted it during late 1990's, while in 2009 it was accepted by as much as $69 \%$ of the members of our society [31].

It also seems interesting to refer the situation in our country in the field of tobacco control activity of companies employing at least 50 employees to the data coming from the U.S. Provisions of tobacco control law $[32,33]$ in that country are in fact more liberal (in most of the municipalities, legal regulations that exercise control over the laws of the companies located within their premises have not implemented any restrictions on smoking). According to the data from the states of Texas and Washington $[32,33]$ illustrating this particular situation from the perspective of a representative sample of members of the Society for Human Resource Management (suitably collected in 2013, 2008, 2015), despite no legal requirements, up to $77-85 \%$ of companies have their internal tobacco control policies, but smoking bans have been introduced on a smaller scale than in our country.

For example, in Texas, only in a half of companies included in the survey, smoking is restricted to designated sites, and regulations completely banning tobacco from indoor spaces and indoor/outdoor areas have been adopted only in every 5th company. However, smoking cessation support activities are undertaken more frequently than in Poland because every 4th company organizes courses of this kind.

In Washington State, such assistance in about every 4th company is in the form of classes or support groups, and about every 3rd company offers insurance covering the costs of medications and medical advice, and in a similar proportion of companies there are procedures that enable 
forcing employees who violate tobacco-control regulations to make use of specialized smoking cessation services. Moreover, in the opinion of 54\% of the U.S. human resource experts, in their companies education on the benefits of not smoking is conducted [32-34]. Polish companies, however, introduce rather bans, well exemplified by the fact that in nearly a half of the companies of the analyzed size there is a total ban on smoking at work, i.e., indoors and outside the building, and the assistance for those who want to liberate themselves from the addiction to nicotine is completely marginalized. Prevention-oriented education activities are also much rarer; they are undertaken by every 6th company. Moreover, the U.S. employers less frequently applied penalties for failure to comply with anti-tobacco regulations than our companies (1\% vs. $12 \%$, respectively).

\section{CONCLUSIONS}

In the light of this data, it seems that companies have eagerly embarked upon the trend of anti-tobacco measures adopted in our country, that involves primarily limiting smoking in public places (regardless of the company's level of employment or its economic condition). They tend to implement the most restrictive form of smoking ban allowed by the modified Tobacco Control Act [15].

Such attitudes of employers are probably enhanced by changing social attitudes, involving the acceptance of the measures taken to reduce the freedom to use tobacco products. This allows the employers to be less afraid of any opposition to such a regulation by the nicotine-dependent employees, and enjoy clearer support from the personnel exposed to second-hand smoke.

This approach helps companies to reduce the phenomenon of second-hand smoke in the workplace, and each reduction of exposure to tobacco smoke should be regarded as a positive phenomenon (although it is worth remembering that the positive consequences are somewhat reduced by the fact that the ban is not always respected). On the other hand, it does not augment, and maybe even hinders voluntary tobacco control activities. Support for voluntary tobacco control offered by medium-sized and large companies is far less frequent than the disciplinary activities, and the situation in that respect has become worse since 2012. Currently, such additional tobacco control activity is an exception and, to make things even worse, it is usually limited to the distribution of leaflets and posters about the dangers of smoking, which is the simplest, classic form of tobacco control through education.

This may suggest that our employers treat tobacco smoking bans primarily as a convenient way to directly deal with the problems of the organization of work (such as a loss of working time) or minimization of costs (e.g., maintenance of premises and equipment, fire safety, provision of smoking rooms) and they use them quite mechanically. The proof is a rare knowledge (existing only in every 3rd company) about the prevalence of tobacco smoking among the personnel and its consequences for the functioning of the company, and also the fact that as many as nearly $2 / 3$ of the companies did not analyze the consequences of the adopted tobacco control regulations. Our employers seem to underestimate, or disregard the impact of smoking (either at work or on the outside) on the health of their personnel (including, e.g., the effect on the efficiency in the performance of official duties, absenteeism, or premature retirement). They also seem to forget about demographic problems, such as, e.g., the aging of the population.

Such approach to solving the problem of smoking also means that employers do not pay due attention to the phenomenon of personnel's commitment to the company (they still believe in the continuance of the employer market). The commitment in of nicotine-dependent workers may be considerably disturbed by their inability to satisfy their needs as a result of the implementation of smoking bans only. Probably the attitude of our employers may also be interpreted in terms of low social commitment. Data on their directly expressed opinions about healthy workplace programs shows that only 1 out of 10 intends 
to reduce the cost of medical care [28]. This type of diagnosis is acceptable and it seems reasonable to permit the matters to take their own course.

On the other hand, considering the fact that the declining trend in the prevalence of smoking in the Polish society has become less evident as well as that data indicating that limiting the places where smoke is allowed has motivated only a few percent of respondents to cease smoking $[14,35]$ (this is a very low rate, even if it is underestimated due to the tendency to eliminate or not to disclose the effect of pressure on decisions) as well as taking into account the low efficiency of traditional educational populationtargeted campaigns [35], it seems that it is worth to remember that, as part of public health policy, it is advisable to take stronger action stimulating employers to implement comprehensive health conservation programs including tobacco control measures. Implementing them right there creates an opportunity to address mainly young workers who are particularly difficult to be involved in local projects and implement more individualized strategies for educational interventions, including those designed for nicotine addicts.

Although the research on the impact of the company (workplace) involvement in the effectiveness of specific methods used in smoking cessation campaigns is not advanced, the accessible results indicate that for a number of those methods the effects are similar, and financial support from the employer (e.g., premiums for not smoking, sponsorship of nicotine replacement therapy, etc.) seems to be particularly motivating [36]. Of course, the adoption of this perspective requires a partnership approach from the state to finance health-promoting activity of companies. So far, it seems unlikely. It also means that there is a need for intensification of educational activities for employers and executives, improving their motivation and ability to support actions intended to improve personnel health. This is in line with the goals of the recent version of the National Health Programme for 2016-2020 [37].
As for the question of quality, i.e., the way in which tobacco control measures should be implemented in the companies, the diagnosis indicates the following challenges:

- encourage companies to better understand the prevalence and patterns of smoking by the personnel (although the interest in this issue is growing, but it is still at an unsatisfactory level, because some sort of the understanding seemed to exist only in every 3rd company);

- encourage companies to take extra-obligatory activities to improve knowledge of personnel about the problem of tobacco use and help to free themselves from nicotine addiction;

- further develop the dialogue with the employees in the area of internal policies on tobacco control (it is advisable to sustain the positive trend in this area and to ensure that the opinions and needs of personnel are reliably recognized);

- stimulate employers to ensure that the rank of tobacco control regulations is sufficiently high by including them in the internal documents (every 3rd medium-sized and large company still do not use this method of action and such situation has prevailed for the last 5 years). A document showing a company's program/strategy for dealing with the problem of smoking by personnel, not just a list of rules restricting smoking, may be quoted as a good example;

- popularize and rationalize the approach to the assessment of the impact of tobacco control measures undertaken by the company (e.g., on the quality of products or services, the social climate in the company and company's repute) to counteract the mechanical implementation of the regulations, or prevent the use of fashionable and not necessarily effective measures.

The presented findings should be confronted with further analyses (the more so that slight differences exist in the selection of the sample and methods of respondents in this study) and made more profound so as to make them more suitable for use by public health decision-makers, for the 
implementation of the next stage of the National Health Programme and for the specialists supporting employers in the management of the company's personnel health.

\section{REFERENCES}

1. Czapiński J, Panek T, editors. [Social diagnosis 2015. Objective and subjective quality of life in Poland]. Contemp Econ. 2015;9(4) [cited 2016 Jul 14]. Available from: http://www.diagnoza.com/pliki/raporty/Diagnoza_raport_2015.pdf. Polish.

2. European Commission. Tobacco or health in European Union. Past, present and future. Belgium: European Communities; 2004 [cited 2016 Jul 14]. Available from: http:// ec.europa.eu/health/ph_determinants/life_style/Tobacco/ Documents/tobacco_fr_en.pdf.

3. Doll R, Peto R, Boreham J, Sutherland I. Mortality in relation to smoking: 50 years' observations on male British doctors. Brit Med J. 2004;328:1519, https://doi.org/10.1136/ bmj.38142.554479.AE.

4. Supreme Audit Office [Internet]. Warszawa: 2013 [cited 2006 Jul 20]. [Implementation of the regulations on protection of health from the effects of use of tobacco and tobacco products]. Available from: https://www.nik.gov.pl/kontrole/wynikikontroli-nik/kontrole,11712.html. Polish.

5. Rentería E, Jha P, Forman D, Soerjomataram I. The impact of cigarette smoking on life expectancy between 1980 and 2010: A global perspective. Tob Control. 2016;25:551-7, https://doi.org/10.1136/tobaccocontrol-2015-052265.

6. Zatoński W, Przewoźniak K, Jaworski JM, Janik-Koncewicz K, Zatoński M. [Free-tobacco workplace. The manual for an empoloyer and employee]. Warszawa: Fundacja Promocja Zdrowia; 2011. Polish.

7. European Network for Workplace Health Promotion. The Luxembourg Declaration on Workplace Health Promotion in the European Union. Essen: BKK; 1997.

8. Shain M, Kramer DM. Health promotion in the workplace: Framing the concept; Reviewing the evidence. Occup Environ Med 2004;61:643-8, https://doi.org/10.1136/oem.2004. 013193.
9. Wengler L, Popowski P, Adamska-Pietrzak E, Balwicka-Szczyrba M, Balwicki Ł, Adrych-Brzezińska I, et al. [Selected aspects of the Polish tobacco control law as a tool for reduction tobacco epidemic]. Ann Acad Med Gedan. 2012;42: 81-94. Polish.

10. Grossmann R, Scala K. Health promotion and organizational development. European Health Promotion. 2nd ed. WHO European Health Promotion. Vienna: IFF/Health and Organizational Development; 1993.

11. Kouvenonen A. Kivimäki M, Oksanen T, Pentti J, Heponiemi T, Väänänen A, et al. Implementation of workplacebased smoking cessation support activities and smoking cessation among employees: The Finnish public sector study. Am J Public Health. 2012;102(7):56-62, https://doi. org/10.2105/AJPH.2012.300823.

12. Koprivnikar H, Korošec A. Age at smoking initiation in Slovenia. Slovenian J Public Health. 2015;54(4):274-81, https:// doi.org/10.1515/sjph-2015-0036.

13. Ekpu VU, Brown AK. The economic impact of smoking and reducing smoking prevalence: Review of evidence. Tob Use Insights. 2015;8:1-35, https://doi.org/10.4137/TUI. S15628.

14. Ministry of Health of the Republic of Poland, World Health Organization [Internet]. Warszawa: The Ministry; 2009-2010 [cited 2016 Jul 14]. [Global Adult Tobacco Survey (GATS)]. Available from: http:/www2.mz.gov.pl/wwwfiles/ma_struktura/docs/sondaz_tyt_15112010.pdf. Polish.

15. [The Act of 9 October 1995 on the protection of health from the effects of use of tobacco and tobacco products]. J Laws 2017, item 957. Polish.

16. [The ordinance of the Minister of Labour and Social Policy on 26 September 1997 on the general regulations on work safety and hygiene]. J Laws 1997, No. 129, item 844. Polish.

17. [The Position of the Labor Protection Council of the Polish Parliament of 14 November 2006]. Warszawa: The Labor Protection Council of the Polish Parliament; 2013.

18. Rantanen J, Kim R. Situation analysis and recommendations for stewardship on workplace health promotion in 
Poland. Copenhagen: World Health Organization, Regional Office for Europe; 2012.

19. Council of Ministers. [Programme for prevention of health effects of tobacco smoking in Poland. Targets and objectives for 2014-2018]. Warszawa: The Council; 2014. Polish.

20. Korzeniowska E, Puchalski K. [The strategy for supporting anti-tobacco activities in Poland. Project on tobacco-free workplace]. Med Pr. 2002;53:485-8. Polish.

21. [The Act of 9 April 2009 amending the Act on the protection of health from the effects of use of tobacco and tobacco products]. J Laws 2010, No. 81, item 529. Polish.

22. European Network for Smoking and Tobacco Prevention [Internet]. Brussels: ENSP; 2016 [cited 2016 Dec 15]. EU Directive on tobacco products. Available from: http://ensp. org./2016/12/01/eu-directive-on-tobacco-products-tpd/.

23. Eurostat [Internet]. Luxembourg: European Commission; 2002 [cited 2016 Dec 15]. Statistical Classification of Economics Activities in the European Community, Rev. 1.1 (2002) (NACE Rev. 1.1). Available from: http://ec.europa.eu/eurostat/ramon/nomenclatures/index.cfm?TargetURL $=\mathrm{LST}_{\text {_ }}$ CLS_DLD\&StrNom=NACE_1_1.

24. Central Statistical Office of Poland [Internet]. Warszawa: The Office; 2007 [cited 2016 Dec 15]. [Polish Classification of Economic Activities (PKD 2007)]. Available from: http:// stat.gov.pl/Klasyfikacje/doc/pkd_07/pkd_07.htm. Polish.

25. Knol-Michałowska K, Petrykowska A, Puchalski K. [E-cigarettes - What are they, how have they emerged, what is the extent of their use and what are the relevant regulations?] [Internet]. Warszawa: Chief Sanitary Inspectoriate; 2014 [cited 2016 Dec 15]. Available from: http://promocjazdrowiawpracy.pl/wp-content/uploads/2014/08/E-Papieros-czymjest-historia-skala-zjwiska-regulacje-prawne.pdf. Polish.

26. Council of Ministers. [Report on the implementation of the programme for prevention of health effects of tobacco smoking in Poland in 2014]. Warszawa: Chief Sanitary Inspectorate; 2015 [cited 2016 Jun 15]. Available from: https://gis.gov.pl/images/sprawozdanie_poznpt_2014.pdf. Polish.
27. Korzeniowska E. The low educated employees towards health - A Polish example. In: Korzeniowska E, Puchalski K, editors. The low educated employees towards health Challenges for health education. Latvia: Riga Stradins University; 2010. p. 116-27.

28. Luxmed, Employers of Poland. [Health in the workplace Diagnosis and expected changes]. Warszawa: Luxmed; 2015. Polish.

29. Wprost.pl [Internet]. [Polish people support the restrictions on tobacco smoking] [cited $2016 \mathrm{Jul}$ 20]. Available from: https://www.wprost.pl/kraj/222593/Polacy-popieraja-ograni czenia-w-paleniu.html. Polish.

30. Huras P. Attitudes to Smoking Cigarettes BS/107.2012. Warszawa: CBOS; 2012.

31. Foundation "Health Promotion". Warszawa: The Foundation; 2011 [cited 2016 Jul 7]. [Workplace free from tobacco smoke. A guidebook for the employer and the employee]. Available from: http://www.sanepid.siedlce.pl/userFiles/do kumenty/ozipz/miejsce_pracy_wolne_od_dymu tytoniowego.pdf. Polish.

32. Stone K, Pry J, Akram H. An overview of tobacco-free policy among worksites in a Central Texas County. Texas Pub Health J. 2013:66(4):18-22.

33. Courtney H, Yette EM, Hannon PA, Harris JR, Tran NM, Reid TR. Promoting tobacco cessation via the workplace: Opportunities for improvement. Tob Control. 2011;20: 305-8, https://doi.org/10.1136/tc.2010.041038.

34. Wessels K, Esen E, Schramm J. Smoking in the workplace. Society For Human Resource Management; 2016 [cited 2016 Jun 15]. Available from: https://www.shrm.org/hr-today/ trends-and-forecasting/research-and-surveys/Documents/ Smoking\%20in\%20the\%20Workplace\%20Survey.pdf.

35. Puchalski K. Poles' opinions on smoking - Do they hinder the decline in its popularity? Probl Hig Epidemiol. 2013;94:215-25.

36. Cahill K, Lancaster T. Workplace interventions for smoking cessation. Cochrane Database Syst Rev. 2014;2:1-4, https:// doi.org/10.1002/14651858.CD003440.pub4. 
37. [Regulation of the Council of Ministers of 7 August 2016 on the National Health Programme 2016-2020]. J Laws 2016, No. 1492. Polish.

This work is available in Open Access model and licensed under a Creative Commons Attribution-NonCommercial 3.0 Poland License - http://creativecommons.org/ licenses/by-nc/3.0/pl/deed.en. 